WSRC-MS-2001-00179

\title{
Design of Metal Hydride Vessels for Processing Tritium
}

by

L. K. Heung

Westinghouse Savannah River Company

Savannah River Site

Aiken, South Carolina 29808

A document prepared for 6TH INTERNATIONAL CONFERENCE ON TRITIUM SCIENCE AND TECHNOLOGY at Epochal Tsukuba, , Japan from 1/11/2002 - 1/16/2002.

DOE Contract No. DE-AC09-96SR18500

This paper was prepared in connection with work done under the above contract number with the $U$. S. Department of Energy. By acceptance of this paper, the publisher and/or recipient acknowledges the U. S. Government's right to retain a nonexclusive, royalty-free license in and to any copyright covering this paper, along with the right to reproduce and to authorize others to reproduce all or part of the copyrighted paper. 
This document was prepared in conjunction with work accomplished under Contract No. DE-AC09-96SR18500 with the U.S. Department of Energy.

\section{DISCLAIMER}

This report was prepared as an account of work sponsored by an agency of the United States Government. Neither the United States Government nor any agency thereof, nor any of their employees, makes any warranty, express or implied, or assumes any legal liability or responsibility for the accuracy, completeness, or usefulness of any information, apparatus, product or process disclosed, or represents that its use would not infringe privately owned rights. Reference herein to any specific commercial product, process or service by trade name, trademark, manufacturer, or otherwise does not necessarily constitute or imply its endorsement, recommendation, or favoring by the United States Government or any agency thereof. The views and opinions of authors expressed herein do not necessarily state or reflect those of the United States Government or any agency thereof.

This report has been reproduced directly from the best available copy.

Available for sale to the public, in paper, from: U.S. Department of Commerce, National Technical Information Service, 5285 Port Royal Road, Springfield, VA 22161

phone: (800) 553-6847

fax: (703) 605-6900

email: orders@ntis.fedworld.gov

online ordering: http://www.ntis.gov/support/index.html

Available electronically at http://www.doe.gov/bridge

Available for a processing fee to U.S. Department of Energy and its contractors, in paper, from: U.S. Department of Energy, Office of Scientific and Technical Information, P.O. Box 62, Oak Ridge, TN 37831-0062

phone: (865)576-8401

fax: (865)576-5728

email: reportseadonis.osti.gov 


\title{
DESIGN OF METAL HYDRIDE VESSELS FOR PROCESSING TRITIUM
}

\author{
L. K. Heung \\ Westinghouse Savannah River Company
}

Aiken, SC 29808

\begin{abstract}
Metal hydrides offer safe, compact and efficient ways to process tritium in areas including storage, pumping, compression, transportation and purification. Westinghouse at Savannah River Site in USA has developed and implemented metal hydride based technology for various tritium applications over the past 20 years. This paper presents our experience in designing different types of metal hydride vessels for tritium processing.
\end{abstract}

\section{Introduction}

Metal hydrides are formed by reacting hydrogen with metals or alloys. The reaction occurs reversibly under moderate hydrogen pressure and temperature for a large group of metals and alloys ${ }^{1}$. The reversible reaction is driven by temperature and hydrogen pressure, and is often called absorption and desorption. These metal hydrides find many applications in the processing of hydrogen isotopes. Metal hydrides can store hydrogen in a solid form under low pressures that offer a safe method for storing tritium. They also can be used to pump/compress hydrogen, to purify hydrogen from other gases and to separate the hydrogen isotopes. All can be done by heat with none or minimal mechanical moving parts. Using metal hydride to process tritium can minimize the potential for tritium release to the environment and to maximize worker safety. At Savannah River Site the tritium facilities process tritium in kilogram quantities. ${ }^{2}$ Protection of the workers and the environment is the highest priority. The hydrogen technology group at Savannah River Site has been actively engaged in the development of metal hydride technology for tritium applications since 1981. Over the years, metal hydride vessels for tritium storage, pumping, compression, transportation, purification and separation have been developed and employed ${ }^{3,4}$. Deigns have also been continuously improved. This paper presents our experience in developing and applying the different types of metal hydride vessels for tritium processing

\section{General Properties of Metal Hydrides and Their Applications}

Metal hydrides became quite well know in the mid seventies due to their potential for safe hydrogen storage in a possible hydrogen economy. To facilitate discussion, several of their key properties are briefly reviewed here. Metal hydrides react with hydrogen isotopes reversibly and the reaction is driven by temperature and hydrogen pressure:

$$
\text { Metal }+\mathrm{H}_{2}, \mathrm{D}_{2}, \mathrm{~T}_{2} \stackrel{\mathrm{P}, \mathrm{T}}{\longleftarrow} \text { Metal hydride }+ \text { heat }
$$


In equation 1, either pressure or temperature can be used as the driving force to control the reaction direction. Most metal hydrides can attain very high density of hydrogen that can be as high as liquid hydrogen. This permits the storing of large amounts of hydrogen in small volumes and the generation of high pressures when heated. This provides the opportunity of using heat to replace mechanical pumps and compressors.

The equilibrium pressures of the three hydrogen isotopes are usually different. When a mixture of the isotopes is at equilibrium with a metal hydride, the ratio of isotopes in the gas phase is different from that in the solid phase. The magnitude of this isotope effect is different from one metal hydride to another. This isotopic effect can be applied to separate hydrogen isotopes. For example, palladium has a very large isotopic effect and has been applied in various isotope separation processes. ${ }^{5}$

When tritium is stored in a metal hydride, the decay helium stays in the solid and does not release until certain concentration has been reached. While this is a convenient way to separate tritium from the decay helium, the retained helium changes the performance of the metal hydride, such as a decrease in equilibrium pressure. ${ }^{6}$ The maximum amount of helium that a metal hydride can retain is known only for a few metal hydrides such as uranium and titanium.

Metal hydrides expand and contract in volume upon hydrogen absorption and desorption, respectively. The volume change can be up to about $20 \%$ depending on material. This volume expansion can generate unacceptable stress on the vessel wall of incorrectly designed vessels. ${ }^{9}$

Most metal hydrides break up to micron size particles upon repeated hydrogen absorption and deorption. The small particles can migrate, compact and pass through incorrectly built filters. Effective filters should confine all the particles in the vessel and create minimal gas flow resistance. The vessel must permit the particles to expand to reduce powder compaction and to avoid stress damage.

Being fine metal particles, metal hydrides can be very reactive to oxygen in air. Limited air exposure reduces the reactivity and capacity of hydrogen absorption. The reactivity can be reinstated but the capacity loss is permanent. Excessive air exposure for most metal hydrides leads to rapid oxidation that can reach red-hot temperatures. ${ }^{10}$

\section{Metal Hydride Vessels Developed at Savannah River Site}

$\underline{\text { Six-mole capacity storage/compressor beds }}$ The first metal hydride vessel designed for tritium service at SRS was a 6-mole capacity storage/compressor. It started tritium storage in 1984 and removed from service in 1986 . The vessel was

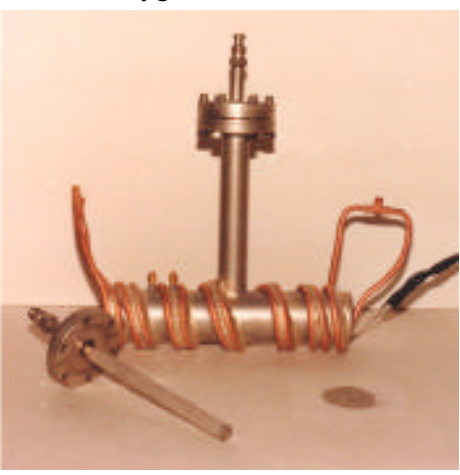

Figure 1. Six-mole capacity storage/compressor bed 
used to store tritium at room ambient and to produce up to 300 psia by heat. The design of such a typical bed is shown in Figure 1. The bed has the general look of an "inverted T". The horizontal body is approximately $3.8 \mathrm{~cm}$ OD and $25 \mathrm{~cm}$ long, making an internal volume of about $300 \mathrm{cc}$. The volume is filled with $1 \mathrm{~kg}$ of metal hydride $\mathrm{LaNi}_{4.7} \mathrm{Al}_{0.3}$. With a bulk density of approximately $4.5 \mathrm{~g} / \mathrm{cc}$, the metal hydride occupied about $75 \%$ of the volume. The $25 \%$ volume is left for volume expansion of the hydride particles. The upward leg of the "inverted $T$ " is the inlet/outlet port. Inside is a cylindrical sintered porous stainless steel filter with a nominal pore size of 5 micron. A copper tube and a sheathed electric heater were coiled and soldered on the outside surface of the bed for cooling and heating. Cold nitrogen gas from a liquid nitrogen dewar is used to cool the bed to as low as $-50{ }^{\circ} \mathrm{C}$. An electric resistance heater with a temperature controller heats the bed up to $150{ }^{\circ} \mathrm{C}$ as needed. The bed can be fully charged with 0.5 atm tritium in less than 30 minutes and generate up to 300 psia pressure when heated to $150{ }^{\circ} \mathrm{C}$. This vessel met all the operation requirements. The main change in performance is that the slope of the plateau has increased due to helium retention.

Seventy-mole capacity storage/pump beds

Following the success of the 6-mole beds, larger beds with capacities up to 70 moles were designed for isotope storage and pumping. These beds are used to store tritium and its isotope mixtures among purification and separation processes. They serve two functions: store the isotopes and deliver (or pump) the isotopes between process units. The basic design is still the "inverted T" concept. A schematic of the design is illustrated in Figure 2. The body of the vessel is a horizontal container fabricated from schedule 40 stainless steel pipe, $7.6 \mathrm{~cm}$ OD and $1 \mathrm{~m}$ long, forming a volume of about 4.4 liters. The vessel is filled with $\mathrm{LaNi}_{4.25} \mathrm{Al}_{0.75}$ to approximately $70 \%$ full. The container is fully enclosed in a 4-inch schedule 10 jacket. A centrally maintained hot and cold nitrogen system is used to heat and cool these hydride beds as needed. The jacket is thermally insulated to reduce heat loss during heating or cooling. These beds can absorb hydrogen at pressures as low as 0.2 bars when cooled and can generate pressures as high as 3 bars when heated. These beds have been in service for more than 5 years. Like the earlier beds, helium retention has cause the plateau slope and operation heel to increase, that reduces the operating capacity. These beds will have to be replaced when the operating capacity becomes too small to meet process requirement.

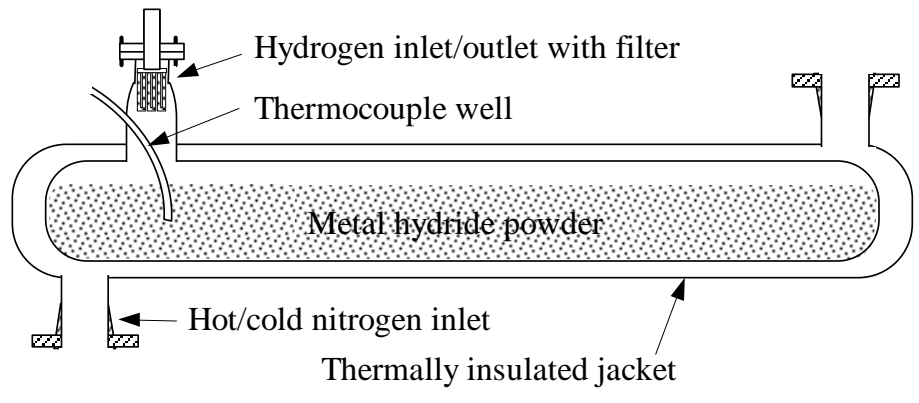

Figure 2. Schematic of seventy-mole capacity storage/pump bed
Thermally insulated tritium storage beds sometimes can generate a temperature and pressure buildup problem. Tritium decay produces 1.95 watt/g. This heat if not removed can 


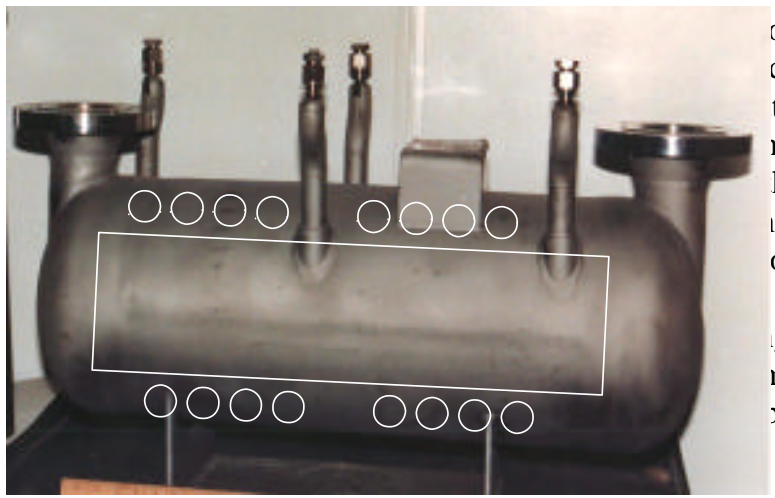

o hundreds of degrees. This high design pressure of the vessel. To $t$ is called the pressure protection Ie pressure. This tank is not a he hydride vessel and the tank. It I the vessel is not cooled. This on requirements.

$\mathrm{g}$ the amount of tritium stored in $\mathrm{n}$ flowing through the jacket is setween the inlet and outlet is a

$\underline{H}$ Figure 4. Hydrogen isotope separation column For separating hydrogen isotopes trom inerts such as helium and nitrogen, a flow-through type of vessel is used. A typical design is shown in Figure 3. The U-shape column is built out of stainless steel pipes up to $8 \mathrm{~cm}$ in diameter. The column is fully jacketed and thermally insulated for heating and cooling using circulation nitrogen. The metal hydride for this application is palladium deposited a kieselguhr which is a porous diatomite. This packing material can withstand hundreds of absorption/desorption cycles without decrepitation. It also has a low flow resistance so that the gas can flow through the column rather freely. The column has an inlet port and an outlet port on top of the legs of

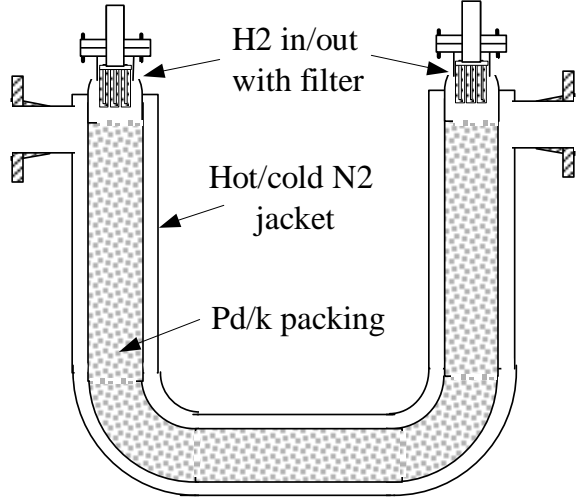

Figure 3. Schematic of U-shape bed for hydrogen purification the U. Both are fitted with porous metal filters that are on top of the packing material so their chance for clogging by fines are minimized. Several of these U-shape columns can be connected in series, in parallel or in combination to form larger units for different process needs.

The operation of this column involves a separation mode and a regeneration mode. In the separation mode the column is cooled to a low temperature. The gas mixture to be purified is fed through the column. The hydrogen isotopes are absorbed and the other gases are collected at the outlet. When the column is saturated, the feed is stopped. The column is heated to desorb the hydrogen isotope that is collected as purified product.

Hydrogen isotope separation column

To separate the hydrogen isotopes from each other, a different column design is applied in a thermal cycling absorption process (TCAP). This TCAP process used the isotopic effect of palladium to separate the isotopes. Its principle of operation has been published. ${ }^{5}$ The process uses a long column filled with palladium deposited on kieselguhr. The column needs to be thermally cycled. To achieve efficient thermal 
cycling, a special coil design is used. A photo of the column design is shown in Figure 4. The long column is formed into a coil to minimize the height of the unit so that it can be easily installed inside a glovebox. The coil is placed in a annular space formed by two concentric cylinders. The inside cylinder is closed so that a heat transfer fluid is forced to flow through the annular space to achieve favorable heat transfer properties. The coil consists of two sections, so that four inlet/outlet ports are available for feed (middle two), product and raffinate. Multi-element porous stainless steel filters are fitted in the inlet/outlet ports to confine the packing material. This design has been in service for over 6 years. High purity products are routinely produced.

Hydride transport vessel

A hydride transport vessel using depleted uranium as the metal hydride was developed for tritium transportation. A picture of the vessel is shown in Figure 5. The vessel body is fabricated from two 4-inch schedule 40 stainless steel pipe caps. This vessel contains $0.5 \mathrm{~kg}$ of depleted uranium and can hold up to 18 grams of tritium. A detailed discussion of the design and performance of this vessel has be published. ${ }^{10}$ This hydride transportation bed has been in service successfully since 1995.

Long term tritium storage vessel

A hydride storage vessel (HSV) was developed for long-term ( $>5$ years) storage of tritium. Titanium in sponge form was selected for this application for its favorable combination of properties that include cost, pressure, stability ${ }^{12}$ and helium retention. Helium retention is important because it permits storing tritium at high concentration without the helium pressure

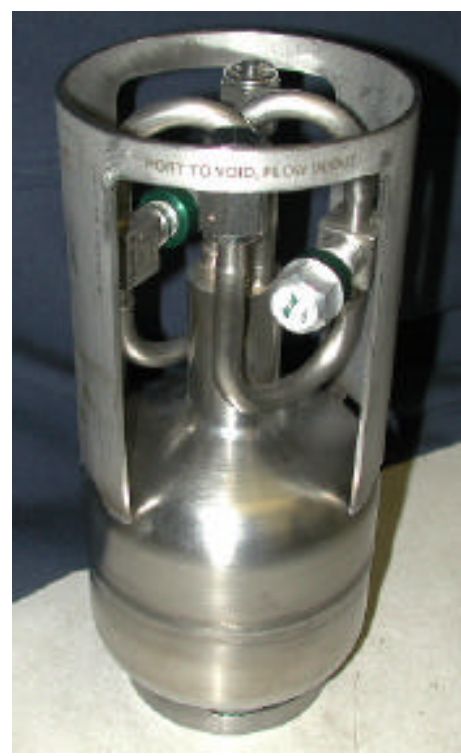

Figure 5. Hydride transport vessel problem. The basic design is an upright vessel of about $17 \mathrm{~cm}$ in diameter and $30 \mathrm{~cm}$ high (6-in schedule 40 stainless steel), plus $20 \mathrm{~cm}$ of valve guard and support. See Figure 6. It contains about $4.5 \mathrm{~kg}$ of titanium and can store 67 moles of tritium for 4 years before helium release occurs. When part of the tritium is replaced by deuterium or protium, its storage time can be increased proportionally. For example, when $1 / 2$ of the 67 moles is protium, the storage life increases to 8 years. This is based on the data reported by A. M $\operatorname{Rodin}^{8}$ that titanium hydride in the $\mathrm{d}$ phase $(\mathrm{H} / \mathrm{Ti}=1.5$ to 2$)$ can retain decay helium up to 0.3 atoms per atom of titanium before releasing. The HSV is designed to stay in storage up to the time when decay helium reaches the 0.3 atom ratio. If permanent storage is the objective, one must assume all the helium will come off in the gas phase. The ultimate helium pressure limits this vessel to store 10 mole of tritium indefinitely. 
Storage vessel with metal foams and dividers

Heat transfer and hydride powder distribution are two most important factors to consider in designing metal hydride vessels. Small diameter vessels are often used to achieve favorable heat transfer rates. However, small diameter vessels are not practical when large capacity beds are required. We have shown that metal foams such as aluminum foams are very effective in improving the heat transfer rate of metal hydride vessels. It was demonstrated that the foam increased the heat transfer rate 5 times in a 9 $\mathrm{cm}$ diameter vessel. ${ }^{13}$ Hydride powder distribution is important because it affects compaction and expansion of the hydride powder. Incorrectly designed vessels can suffer damage by the compaction and expansion of the hydride powder. We have demonstrated that maintaining uniform distribution of the hydride powder in a partly filled horizontal vessel is important. ${ }^{9}$ An excellent way to

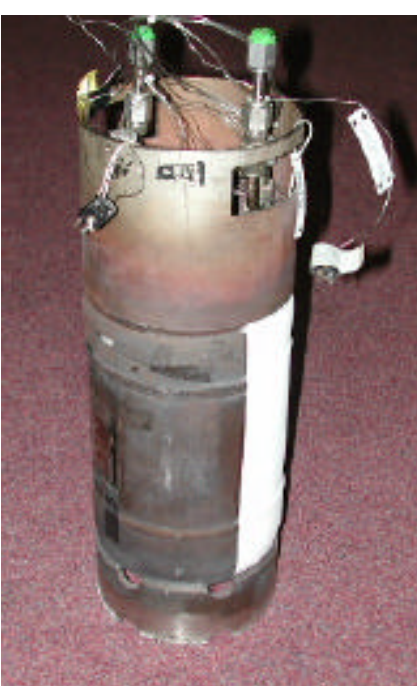

Figure 6. Hydride storage vessel for long term tritium storage keep the powder distributed uniformly even in a mobile situation is to use divider plates. The plates separate the length of the vessel into sections so that the length of each section

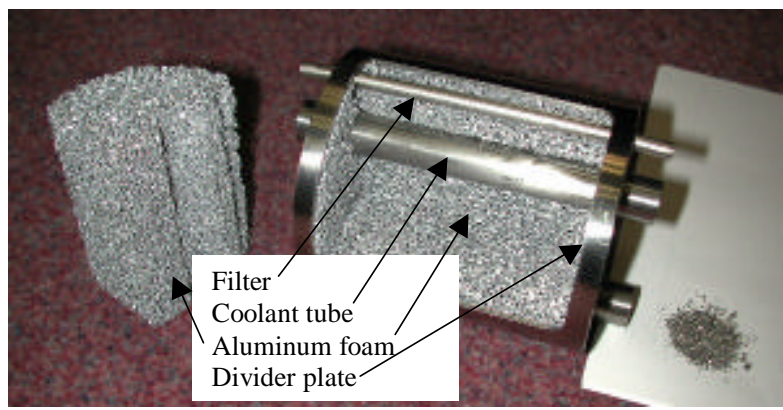

Figure 7. Model of hydride vessel with foam and divider plate is approximately the same as the diameter of the vessel. With the metal foams and the divider plates, we have designed several improved metal hydride vessels. The first was a hydrogen storage vessel targeted for mobile hydrogen storage applications. A model section of its construction is illustrated in Figure 7. The vessel is a horizontal thin wall stainless steel tube with diameter of about $9 \mathrm{~cm}$ and length of about $1.5 \mathrm{~m}$. Aluminum plates divide the length into compartments with width approximately equal to the diameter of the vessel. Open cell aluminum foams filled each compartments. Metal hydride powder occupies the open cells of the foam. A porous metal tube positioned near the top of the vessel penetrate each compartment is the inlet/outlet for the hydrogen gas. A U-shape coolant tube runs the length of the vessel for circulating heat transfer medium. The metal foam improves the heat transfer in the hydride bed that permits the use of the small U-shape coolant tube to replace a full jacket. The weight of the vessel is significantly reduced. Performance of a vessel with this design has been published. ${ }^{13}$ 
Another hydride vessel with these improved features is the "passively cooled electrically heated" tritium storage bed. The design of this vessel is shown in Figure 8. The use of foam and divider is the same as the above vessel. The differences are that electric heaters in heater wells are for heating, and that a full vacuum jacket is used for thermal insulation during the heating cycle. During the cooling cycle, the jacket is open to ambient or to forced gas circulation to provide the cooling. This design reduces the heating/cooling requirements and alleviates the temperature and pressure problem

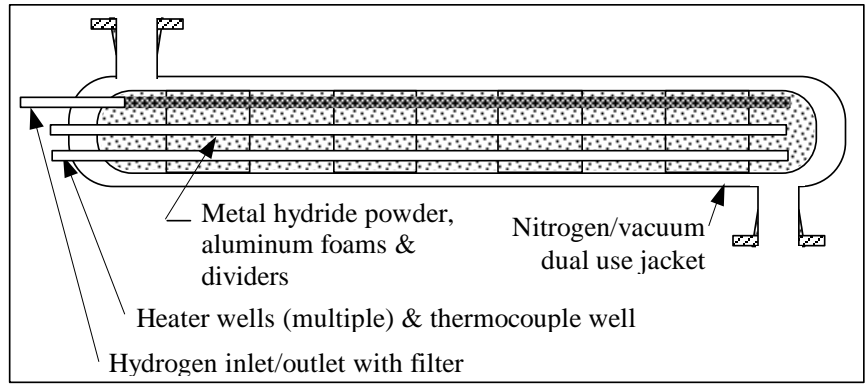

Figure 8. Tritium storage bed with electric heat and ambient cool caused by the tritium decay heat.

\section{Absorption Rate And Heat Transfer Of Metal Hydride Vessels}

Hydrogen absorption rate and heat transfer of a metal hydride vessel are closely related. In general the kinetic of hydride forming is fast, but the heat transfer is slow and limiting. The following analysis is an example. The rate of the hydride forming reaction is a function of temperature, hydrogen pressure and degree of saturation. The temperature increases the kinetics but also increase the equilibrium pressure that reduces the pressure driving force. The pressure driving force is defined by the difference between the hydrogen pressure and the equilibrium pressure. Degree of saturation can be measured by the difference between the maximum H/M (hydrogen to metal atom ratio) and the current $\mathrm{H} / \mathrm{M}$. The farther from saturation the faster is the hydride forming reaction. For the $\mathrm{LaNi}_{4.25} \mathrm{Al}_{0.75}$ system it was found that an unreacted-core model applied. The following rate equation was derived ${ }^{14}$ :

$$
\mathrm{R}_{\mathrm{a}}=\mathrm{k}_{\mathrm{o}} \exp ^{(-\mathrm{E} / \mathrm{RT})}\left(\mathrm{P}_{\mathrm{H}}-\mathrm{P}_{\mathrm{D}}\right)\left(?\left((\mathrm{H} / \mathrm{M})_{\max }-(\mathrm{H} / \mathrm{M})\right)\right)^{2 / 3}
$$

where $\mathrm{R}_{\mathrm{a}}$ is the hydride forming rate, $\mathrm{STP}$ liter $/ \mathrm{min} / \mathrm{kg}$ of metal, $\mathrm{k}=0.0656, \mathrm{E}=1.07$ $\mathrm{kcal} / \mathrm{moe}, \mathrm{R}=1.987 \mathrm{cal} / \mathrm{mol} /{ }^{\circ} \mathrm{K}, \mathrm{P}_{\mathrm{H}}=$ hydrogen pressure, torr, $\mathrm{P}_{\mathrm{D}}$ desorption pressure, torr, from isotherm correlation, ? =bulk density of metal hydride particles, $4.2 \mathrm{~kg} / \mathrm{liter}$, $(\mathrm{H} / \mathrm{M})_{\max }=0.92$. Equation 2 permits the calculation of hydride forming rate at different temperature, pressure and saturation. The saturation time at different hydrogen pressures, with the temperature kept constant at $40{ }^{\circ} \mathrm{C}$, was calculated and plotted in Figure 9. The results show that saturation is fast and can be reached within a few minutes. This fast absorption time is seldom realized in real application because of heat transfer limitation. In the same study ${ }^{14}$, it was shown that for a $8-\mathrm{cm}$ diameter vessel the heat transfer coefficient $(h)$ is correlated to hydrogen pressure $\left(\mathrm{P}_{\mathrm{H}}\right)$ : 


$$
\begin{aligned}
& \mathrm{h}=33.8 \log \mathrm{P}_{\mathrm{H}}-47.8 \quad \mathrm{~W} / \mathrm{m}^{2} /{ }^{\circ} \mathrm{K} \quad \text { for } \mathrm{P}_{\mathrm{H}}>50 \text { torr } \\
& =10.2 \quad \mathrm{~W} / \mathrm{m}^{2} /{ }^{\circ} \mathrm{K} \quad \text { for } \mathrm{P}_{\mathrm{H}}=50 \text { torr }
\end{aligned}
$$

With equation 3 , the saturation time is calculated for different hydrogen pressure and listed in Table 1. The results show that with $20{ }^{\circ} \mathrm{C}$ coolant, hundreds of minutes is required to reach saturation. Comparing these saturation times with that in Figure 9, it is clear that heat transfer is very limiting. Heat transfer is an important factor to consider in designing metal hydride vessels.

\section{Summery and Conclusions}

Metal hydrides offer a great opportunity for improvement in tritium processing. They permit the design of safe, compact and efficient tritium handling equipment. Westinghouse at Savannah River Site has used this opportunity to develop a number of tritium applications. Since 1981 metal hydride vessels have been developed for applications from storage, pumping, compression, purification, and separation to transportation. Heat transfer, fines confinement, powder compaction and expansion, are the important factors to consider in designing hydride vessels. Designs of successful vessels have been presented in this paper. The information should be helpful to readers who have the need to develop new metal hydride applications.

\section{Acknowledgment}

This paper was prepared in connection with work done under Contract No. DE-AC0989SR18035 with the U.S. Department of Energy.

\section{Reference}

1. G. Thomas and G. Sandrock, Hydride Information Center, web site: http://hydpark.ca. sandia.gov.

2. R. D. Buley and D. J. Green,

\begin{tabular}{|c|c|c|c|c|c|}
\hline Hydrogen Pressure, (torr) & 50 & 100 & 300 & 500 & 760 \\
\hline $\begin{array}{l}\text { Heat transfer coefficient, } \\
\qquad\left(\mathrm{W} / \mathrm{m}^{2} /{ }^{\circ} \mathrm{K}\right)\end{array}$ & 9.6 & 19.8 & 35.9 & 43.4 & 49.6 \\
\hline $\begin{array}{l}\text { Heat removal rate at } \\
? \mathrm{~T}=(40-20){ }^{\circ} \mathrm{C},\left(\mathrm{W} / \mathrm{m}^{2}\right)\end{array}$ & 193 & 396 & 719 & 869 & 991 \\
\hline $\begin{array}{c}\text { Absorption rate at ? } \mathrm{H}=10 \\
\mathrm{kcal} / \mathrm{mol},(\mathrm{STP} \text { liter } / \mathrm{min} / \mathrm{kg} \text { ) }\end{array}$ & 0.09 & 0.19 & 0.35 & 0.43 & 0.49 \\
\hline Time to saturation, (minutes) & 1599 & 777 & 428 & 354 & 311 \\
\hline
\end{tabular}

Table 1. Heat transfer effect on absorption rate 
"Tritium processing and contaiment at the Savannah River Site", Fusion Technology, vol 28, October 1995.

3. M. S. Ortman, L. K. Heung, A. Nobile, and R. L. Rabun III, "Tritium processing at the Savannah River Site: Present and future”, J Vac. Sci. Technol. A 8(3), May/Jun 1990.

4. T. Motyka, “The Replacement Tritium Facility”, Fusion Technology, 21(2), March 1992.

5. A. S. Horen, and M. W. Lee, "Metal hydride based isotope separation-large-scale operatios”, Fusion Technology, vol 21,March 1992.

6. R. T. Walters, "Helium dynamics in metal tritides 1 . The effect of he.ium from tritium decay on the desorption plateau pressure for La-Ni-Al tritides", J. Less-Comm Metals, 157, 97(1990).

7. M. E. Malinnowske and P. R. Coronado, "Helium release from uranium tritide", Radiation Effects and Tritium Technology for Fusion Reactors, Oak Ridge National Laboratory, CONF-750989, vol IV, 1976.

8. A. M. Rodin and V. V. Surenyants, "Solid solutions of helium in titanium containing up to 30 at.\% of helium", Russian J. of Physical Chemistry, 45(5), 1971.

9. S. T. McKillip, C. E. Banister and E. A. Clark, "Stress analysis of hydride vessels used for tritium storage", Fusion Technology, vol 21, p1011, March 1992.

10. L. K. Heung, “Tritium transposrt vessel using depleted uranium”, Fusion Technology vol 28, p1385, October 1995.

11. J. E. Klein, "In-bed accountability of tritium in production scale metal hydride storage beds", Fusion Technology vol 28, p1026, 1995.

12. J. M. Miller, W. J. Holtstander, R. E. Johson and W. R. Taylor, "Safe and compact storage and transportation of tritium as titanium tritide", Proceedings of Canadian Nuclear Society $2^{\text {nd }}$ International Coference on Radioactive Waste Management, September 7-11, 1986.

13. L. K. Heung, "On-board hydrogen storage system using metal hydride", in T. O. Saetre (editor), Hydrogen Power: Theroretical and Engineering Solutions, 251-256, 1998.

14. L. K. Heung, "Heat transfer and kinetics of a metal hydride reactor", Metal-hydrogen systems fundamentals and applications, proceedings edited by R. Kirchheim et al, 1415-1420, 1989. 